\title{
Angioimmunoblastic T-Cell Lymphoma with Polyarthritis Resembling Rheumatoid Arthritis
}

\author{
Ralph Yachoui, MD; Nouman Farooq, MD; Jonathan V. Amos, MD; and Gene R. Shaw, MD
}

\begin{abstract}
Angioimmunoblastic T-cell lymphoma (AITL) is a rare subtype of peripheral T-cell lymphoma (PTCL). AITL typically presents with lymphadenopathy, fever, rash, hepatosplenomegaly, and rarely polyarthritis. We report the case of a 50-year-old female who presented with lymphadenopathy, rash, and symmetric polyarthritis. She was later diagnosed with AITL and was treated with chemotherapy with resolution of arthritis. AITL should be suspected in paitents presenting with rheumatoid-like arthritis and diffuse lymphadenopathy.
\end{abstract}

Keywords: AITL; Angioimmunoblastic T-cell lymphoma; Lymphadenopathy; Polyarthritis; Rheumatoid arthritis

\begin{abstract}
$\Lambda$ ngioimmunoblastic T-cell lymphoma (AITL) is a rare subtype of peripheral T-cell lymphoma (PTCL) that was first described in $1975 .{ }^{1}$ AITL typically presents with the acute onset of a multisystem illness characterized by generalized lymphadenopathy, rash, splenomegaly, and classic B symptoms of lymphoma including fevers, night sweats, and weight loss. ${ }^{1}$ The incidence of AITL is extremely low, with only 0.05 new patients in every 100,000 people in the United States. $^{2}$ Patients with AITL uncommonly develop a paraneoplastic polyarthritis mimicking rheumatoid arthritis. ${ }^{3,4}$ AITL-related arthritis can appear before, concurrently with, or soon after the diagnosis of AITL. Herein, we report the clinicopathologic characteristics of a patient presenting with newly diagnosed AITL-associated arthritis.
\end{abstract}

\section{Case Report}

A 50-year-old Caucasian woman presented to the rheumatology clinic with a 1-month history of polyarthritis accompanied by rash and lymphadenopathy. She had no known history of arthralgias, arthritis, or autoimmune phenomena. Her joint pain was bilateral and symmetric and involved the foot, ankle, knee, elbow, and hand. Her lymphadenopathy progressed from the cervical region and became more diffuse. The rash was pruritic and generalized. She denied weight loss, night sweats, or fevers. She had a history of hypertension, dyslipidemia, and depression. Medications included metoprolol, simvastatin, irbesartan/hydrochlorothiazide, and citalopram. Her father had colon, prostate, and kidney cancers, and a paternal grandmother had ovarian cancer; there was no family history of hematologic malignancies or rheumatic diseases. She worked in an office performing filing duties. She did not have any unusual environmental exposures. She drank alcohol occasionally and was a lifetime nonsmoker.

At presentation, the patient was afebrile, and her vitals were stable. Marked synovitis of the metacarpophalangeal, proximal interphalangeal, wrist, elbow, knee, foot, and ankle joints was detected. Shoulder and hip motion was unrestricted. There was bilateral cervical, axillary, and inguinal lymphadenopathy and generalized erythematous skin rash. Laboratory results were normal for complete blood count, comprehensive metabolic panel, and serum lactate dehydrogenase. Tests including anti-nuclear antibody, anti-neutrophil cytoplasmic antibody, rheumatoid factor, anti-cyclic citrullinated peptide, C3 and C4 levels, hepatitis B surface antigen, and hepatitis C antibody were negative or within normal range. Erythrocyte sedimentation rate was $37 \mathrm{~mm} / \mathrm{hr}$ (normal, $0-17 \mathrm{~mm} / \mathrm{hr}$ ). Serum protein electrophoresis revealed a polyclonal hypergammaglobulinemia; serum free light chain ratio was normal.

Initial plain radiographs of her hands and feet showed findings most consistent with mild generalized osteoarthritis with absence of erosions (figure 1). Right knee arthrocentesis yielded $20 \mathrm{cc}$ of yellow fluid, and synovial fluid analysis revealed 1,185 white blood cells (44\% neutrophils, 32\% lymphocytes) with no crystals and negative gram stain and culture. Computed tomography scans of her chest, abdomen, and pelvis demonstrated widespread lymphadenopathy and mild splenomegaly. A bone marrow biopsy showed trilineage hematopoietic maturation and no convincing evidence for involvement by a neoplastic process.
Corresponding Author: Ralph Yachoui, MD, Department of Rheumatology, Marshfield Clinic, 1000 N. Oak Avenue, Marshfield,WI 54449 USA, Tel: (7I5) 387-5 190 , Email: yachoui.ralph@marshfieldclinic.org
Received: June 19, 2016

Revised: September 29, 2016

Accepted: October 24, 2016

doi: $10.3121 / \mathrm{cmr} .2016 .1334$ 

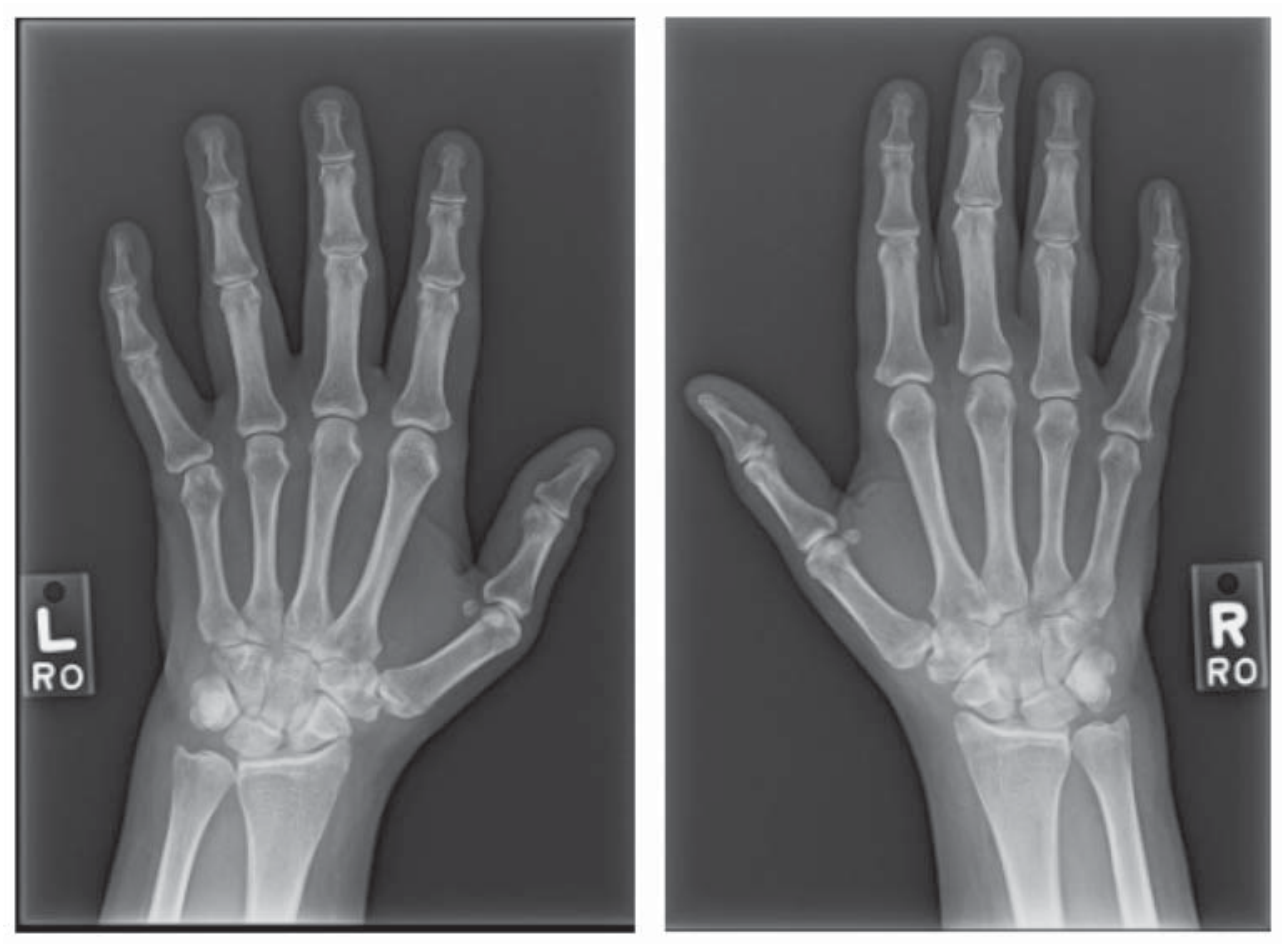

Figure 1. Mild cartilage space narrowing is seen at the interphalangeal joints with absence of erosions.

A biopsy of a right cervical node showed complete effacement by a peripheral T-cell lymphoma with characteristic features of angioimmunoblastic T-cell lymphoma (AITL).

Histologic findings showed a marked proliferation of small to medium-sized lymphocytes with clear cytoplasm and distinct cell membranes, in addition to moderate amounts of arborizing high endothelial venules (figure 2A). Immunohistochemistry demonstrated a diffuse predominance of CD3-positive T-cells (figure 2B). Flow cytometry showed the CD3-positive T-cells to be largely CD4-positive with a subset having dim CD10 coexpression (figure 2C). CD21 demonstrated the expanded follicular dendritic cell networks characteristic of AITL (figure 2D). She was treated with CHOP (cyclophosphamide, doxorubicin, vincristine, and prednisone) regimen, to which she responded very well, with resolution of lymphadenopathy, significant reduction in peripheral joint pain and swelling, and improvement in function.

\section{Discussion}

AITL is a rare disease that accounts for about $1 \%$ to $2 \%$ of all non-Hodgkin's lymphomas and $15 \%$ to $20 \%$ of PTCLs. ${ }^{3}$ AITL equally affects men and women; the median age is approximately 60 to 65 years. AITL has a poor prognosis, with a relapse rate of $56 \%$, median survival of 36 months, and 5-year survival of $36 \%{ }^{4}$ Immunological abnormalities are frequent and include polyarthritis, polyclonal hypergammaglobulinemia, cryoglobulinemia, autoimmune hemolytic anemia, and autoimmune thyroid disease. ${ }^{5}$
Histologically, AITL typically shows a polymorphous infiltrate comprising immunoblasts, plasma cells, small lymphocytes and eosinophils with an expanded follicular dendritic cell network, and prominent vascularization with arborizing high endothelial venules. ${ }^{5}$

The association between malignancy and rheumatic diseases is complex and intriguing. Paraneoplastic joint diseases have variable presentations and can be important clues to occult neoplasia. ${ }^{6}$ In the absence of a defined pathogenic link between the malignancy and the rheumatic syndrome, the association between these diseases is mainly based on a suggestive temporal concurrence and a parallel clinical course. ${ }^{7}$ A paraneoplastic polyarthritis in association with AITL is uncommon. ${ }^{8-12}$ It usually involves the proximal interphalangeal, metacarpophalangeal, wrist, ankle, foot, and knee joints. ${ }^{8}$ AITL-associated arthritis is usually a nonerosive, nondeforming, seronegative, and symmetric polyarthritis of explosive onset, accompanied by constitutional symptoms and elevated markers of inflammation. ${ }^{8-10}$ It is important to differentiate this entity from other immune-mediated chronic inflammatory conditions such as systemic lupus erythematosus, Sjogren's disease, rheumatoid arthritis, and adult onset Still's disease.

Initial treatment options for AITL include combination chemotherapy with or without glucocorticoids, autologous hematopoietic cell transplantation, and investigational therapies. The arthritis associated with AITL usually responds well to low-moderate doses of steroids and does not require 
A.

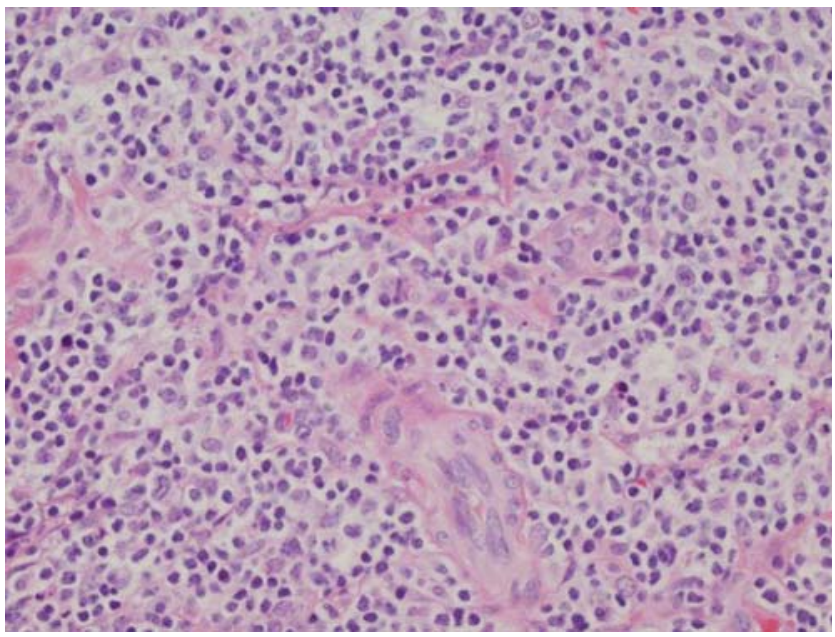

B.

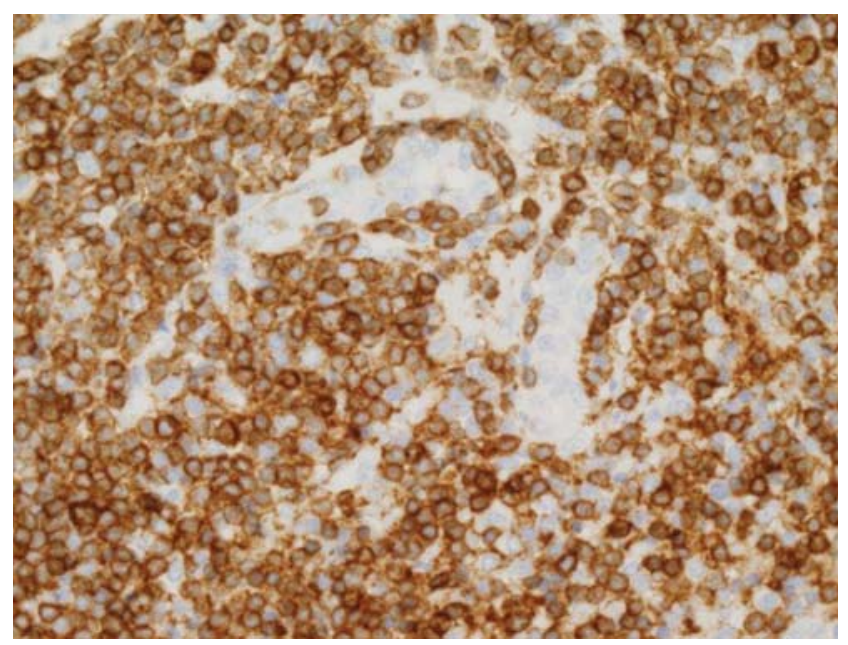

C.

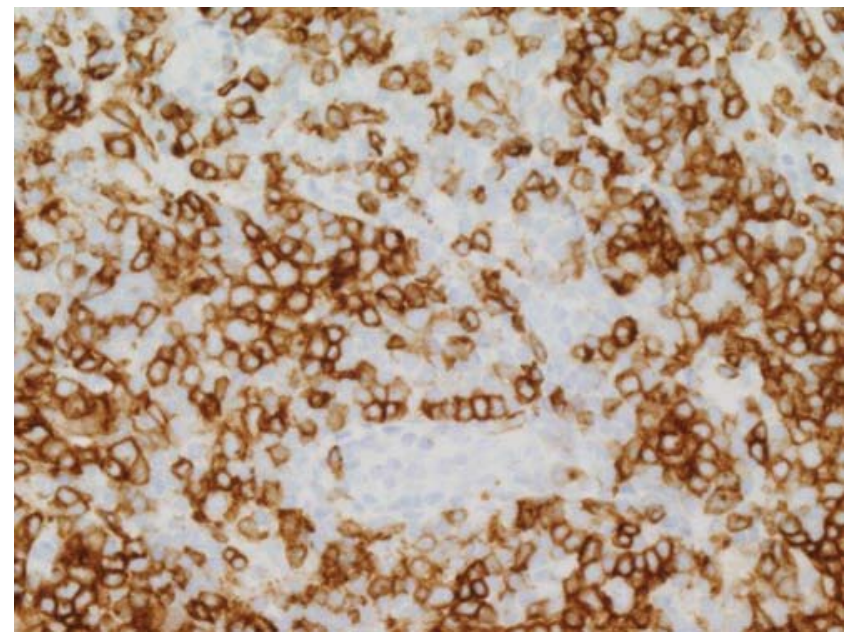

D.

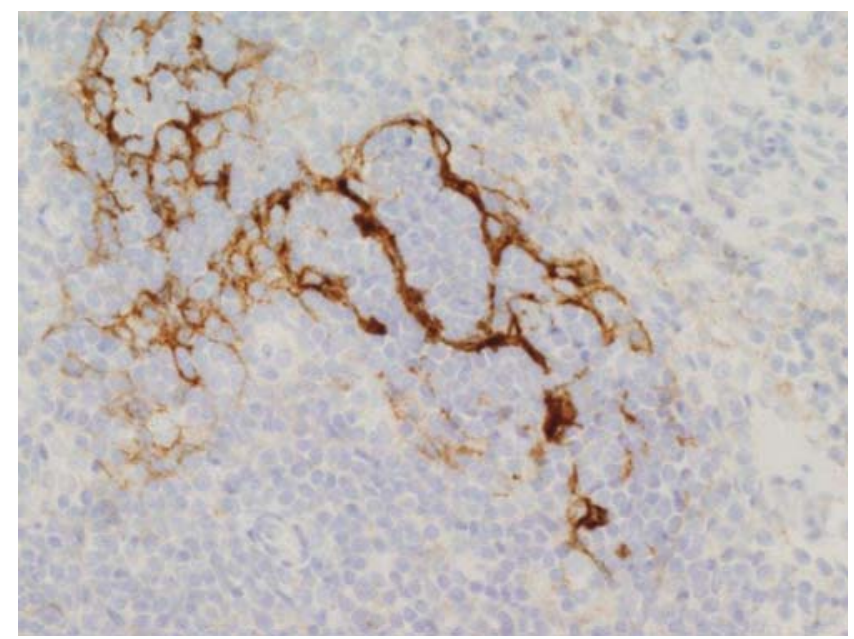

Figure 2. (A) Histology of a lymph node showing numerous small lymphocytes with clear cytoplasm and distinct membranes and scattered high endothelial venules (hematoxylin \& eosin). (B) Immunohistochemistry staining revealing a diffuse predominance of CD3-positive T-cells with (C) a subset having dim CD10 coexpression. (D) CD21 staining showing a follicular dendritic cell network associated with clear cells and high endothelial venules. Original magnification, x400.

the use of synthetic or biologic disease-modifying antirheumatic drugs. The presence of arthritis does not influence survival in patients with AITL. ${ }^{13}$ New evidence suggests that follicular helper T-cells (Tfh cells) are the cells of origin of AITL. ${ }^{14}$ Tfh cells, which are a relatively new subset of CD4+ $\mathrm{T}$ cells, have also been implicated in several autoimmune conditions, including systemic lupus erythematosus ${ }^{15}$ and rheumatoid arthritis. ${ }^{16}$ Therefore, Tfh cells could explain the pathogenic link between AITL and its associated immunological abnormalities. Novel therapies targeting Tfh cells currently undergoing pre-clinical evaluation and early phase clinical trials may potentially find a place in the treatment of Tfh lymphomas such as AITL. ${ }^{14-17}$

\section{References}

1. Frizzera G, Moran EM, Rappaport H. Angio-immunoblastic lymphadenopathy. Diagnosis and clinical course. Am J Med. 1975;59:803-818.

2. Morton LM, Wang SS, Devesa SS, Hartge P, Weisenburger DD, Linet MS. Lymphoma incidence patterns by WHO subtype in the United States, 1992-2001. Blood. 2006;107:265 276.

3. Federico M, Rudiger T, Bellei M, Nathwani BN, Luminari S, Coiffier B, Harris NL, Jaffe ES, Pileri SA, Savage KJ, Weisenburger DD, Armitage JO, Mounier N, Vose JM. Clinicopathologic characteristics of angioimmunoblastic T-cell lymphoma: analysis of the international peripheral T-cell lymphoma project. J Clin Oncol. 2013;31:240-246.

4. Pautier P1, Devidas A, Delmer A, Dombret H, Sutton L, Zini JM, Nedelec G, Monlina T, Marolleau JP, Brice P. Angioimmunoblastic-like T-cell non-Hodgkin's lymphoma: outcome after chemotherapy in 33 patients and review of the literature. Leuk Lymphoma. 1999;32:545 552. 
5. Dogan A, Attygalle AD, Kyriakou C. Angioimmunoblastic T-cell lymphoma. Br J Haematol. 2003;121:681-691.

6. Naschitz JE, Rosner I. Musculoskeletal syndromes associated with malignancy (excluding hypertrophic osteoarthropathy). Curr Opin Rheumatol. 2008;20:100-105.

7. Racanelli V, Prete M, Minoia C, Favoino E, Perosa F. Rheumatic disorders as paraneoplastic syndromes. Autoimmun Rev. 2008;7:352-358.

8. Tsochatzis E, Vassilopoulos D, Deutsch M, Filiotou A, Tasidou A, Archimandritis AJ. Angioimmunoblastic T-cell lymphomaassociated arthritis: case report and literature review. J Clin Rheumatol. 2005;11:326-328.

9. Layton MA, Musgrove C, Dawes PT. Polyarthritis, rash and lymphadenopathy: case reports of two patients with angioimmunoblastic lymphadenopathy presenting to a rheumatology clinic. Clin Rheumatol. 1998;17:148-151.

10. McHugh NJ, Campbell GJ, Landreth JJ, Laurent MR. Polyarthritis and angioimmunoblastic lymphadenopathy. Ann Rheum Dis. 1987;46:555-558.

11. Rothwell RS, Mant MJ, Davis P. Angioimmunoblastic lymphadenopathy associated with polyarthritis. Ann Rheum Dis. 1980;39:406-409.

12. Notas G, Xylouri I, Kritikos H, Stavroulaki E, Roditakis G, Boumpas D. A rare case of angioimmunoblastic T-cell lymphoma presenting with fever and late polyarthritis. Rheumatology (Oxford). 2009;48:859-862.

13. Siegert W, Nerl C, Agthe A, Engelhard M, Brittinger G, Tiemann M, Lennert K, Huhn D. Angioimmunoblastic lymphadenopathy (AILD)-type T-cell lymphoma: prognostic impact of clinical observations and laboratory findings at presentation. The Kiel Lymphoma Study Group. Ann Oncol. 1995;6:659-664.

14. Ahearne MJ, Allchin RL, Fox CP, Wagner SD. Follicular helper T-cells: expanding roles in T-cell lymphoma and targets for treatment. Br J Haematol. 2014;166:326-335.

15. Le Coz C, Joublin A, Pasquali JL, Korganow AD, Dumortier H, Monneaux F. Circulating TFH subset distribution is strongly affected in lupus patients with an active disease. PLoS One. 2013;8:e75319.

16. Ma J, Zhu C, Ma B, Tian J, Baidoo SE, Mao C, Wu W, Chen J, Tong J, Yang M, Jiao Z, Xu H, Lu L, Wang S. Increased frequency of circulating follicular helper T cells in patients with rheumatoid arthritis. Clin Dev Immunol. 2012;2012:827480.

17. Platt AM, Gibson VB, Patakas A, Benson RA, Nadler SG, Brewer JM, McInnes IB, Garside P. Abatacept limits breach of self-tolerance in a murine model of arthritis via effects on the generation of $\mathrm{T}$ follicular helper cells. J Immunol. 2010;185:1558-1567.

\section{Author Affiliations}

Ralph Yachoui, MD*; Nouman Farooq, MD ; Jonathan V. Amos, MD†; and Gene R. Shaw, MD

*Department of Rheumatology, Marshfield Clinic, Marshfield, Wisconsin USA.

†Department of Internal Medicine, Marshfield Clinic,

Marshfield Wisconsin USA

tDepartment of Pathology, Marshfield Clinic, Marshfield

Wisconsin USA 